\title{
Las Reflexiones (1761) de Simón de Aragorri y la reforma del comercio atlántico español
}

\author{
por \\ Jesús Astigarraga \\ Departamento de Estructura e Historia Económica y Economía Pública \\ Universidad de Zaragoza
}

Las Reflexiones sobre el estado actual del comercio de España es un amplio tratado político-económico, hasta la fecha desconocido, publicado en 1761 bajo la autoría anónima de Simón de Aragorri. El hallazgo de un ejemplar del mismo permite apreciar que su objetivo era incidir en el debate económico abierto tras la entronización de Carlos III. En este trabajo se analizan los fundamentos teóricos y la propuesta reformadora planteada en el libro respecto a los territorios de ultramar.

PALABRAS ClaVE: circulación internacional de las ideas politico-económicas; historia atlántica; Ilustración española; reformas económicas; Jacques Accarias de Serionne; David Hume.

\section{INTRODUCCIÓN*}

En el otoño de 1765, en un relevante documento oficial elaborado a la sombra de Grimaldi y Esquilache, al enjuiciar la situación que atravesaba la población de los territorios españoles en las Indias, se sostenía que se estaba materializando de una manera imperceptible «la independencia de aquellos vasallos», debido a que, poseyendo "dentro de sus países lo que necesitan, será difícil mantenerlos dependientes sin la mutua comunicación de frutos y efectos» ${ }^{1}$. Esta afirmación, tan rotunda como certera, reflejaba muy bien el

* Este trabajo se integra en el Proyecto de Investigación HAR2011-29036-C02-01. Una visión previa sobre el mismo se presenta en un Documento de Trabajo publicado por la Asociación Española de Historia Económica (Astigarraga, 2011).

1 Consulta hecha a su Magestad en Junta formada de su Real Orden por el Marqués de Llanos, D. Francisco Craywinkel, D. Simón de Aragorri, D. Tomás Ortiz de Landázuri 
estado de preocupación que recorría los aledaños del poder político español poco después de la llegada al trono de Carlos III respecto a la suerte futura de esos territorios trasatlánticos. De hecho, se trataba de una más de otras valoraciones de gravedad similar, que integraban una extensa Consulta redactada por una Junta Especial, creada por iniciativa de esos dos influyentes ministros del nuevo Rey, en julio de 1764 y presidida por el Marqués de Llanos, para estudiar el «grande atraso» en el «comercio que hace España con sus propias colonias y con los Reinos extranjeros». Como es bien conocido, esa Consulta, finalizada en febrero de 1765, sirvió como guía en la elaboración, pocos meses después, del Reglamento del comercio libre, la primera revisión sustancial del sistema transatlántico español de todo el siglo XVIII y punto de arranque del denominado ciclo del comercio libre, que, prolongado después a través de otros dos reglamentos, de 1778 y 1789, configurará la dinámica esencial de las reformas que desde la metrópoli española trataron de encauzar la difícil situación por la que mediado ese siglo atravesaban sus relaciones con sus extensos territorios ultramarinos ${ }^{2}$.

Como ponía de relieve crudamente la cita extraída de la Consulta, el temor a una posible «independencia» de los españoles americanos procedía principalmente de la dudosa certeza respecto a la capacidad para mantenerlos «dependientes» de la metrópoli a través de la «comunicación de los frutos y efectos», es decir, del comercio. De esta manera, esa cita reflejaba a la perfección el clima del notable debate que España conoció durante el ciclo del comercio libre - esto es, el reinado de Carlos III- con el fin de «descubrir las verdaderas causas de nuestra decadencia en el comercio y navegación ${ }^{3}$. Precisamente, el argumento central del mismo fueron las reformas económicas y comerciales, sin duda con una proyección indiscutible sobre la esfera política, pero relegando a la posterioridad las más genuinas de esa naturaleza, bien la libertad política o bien las relativas a la soberanía o los derechos individuales, ninguna de las cuales, como venían mostrando con claridad los ejemplos inglés u holandés, se hallaba reñida con la pujanza comercial.

Sobre ese debate, por tanto, esencialmente económico, se proyectaba la sombra de que la Monarquía española estaba siendo incapaz de aprovechar en su beneficio su extraordinario poder ultramarino; una sombra para entonces

y D. Pedro Gossens sobre el comercio interior y exterior de España con sus colonias de América y sus provincias, 1765, Archivo del Palacio Real (APR), Madrid, II/2639, fol. $15 \mathrm{v}$.

2 Sobre esta cuestión, bien estudiada, pueden verse, por ejemplo: García-Baquero, 1976: vol. I, 210 y ss. Llombart, 1992: 113-153. Stein y Stein, 2005: 83-95. Delgado, 2007: 235-277.

3 Consulta hecha a su Magestad... APR, II/2639, fol. 3. 
secular, además de no ajena a una influyente nómina de escritores, comenzando por algunos extranjeros notables, desde Child, Petty o Davenant en Gran Bretaña hasta Montesquieu en Francia ${ }^{4}$. Los resultados de la Junta Especial de 1764 pusieron de relieve que sus miembros participaban plenamente de la corriente crítica con los modos de gestionar ese poder que se había ido abriendo paso desde la España de Felipe $\mathrm{V}^{5}$, primero de la mano de Uztáriz, Marcenado o Zavala, y, con posterioridad, a través de ese conjunto de escritos debidos a funcionarios y políticos de alto rango, buena parte de ellos manuscritos, que desde los años cuarenta fueron creando el sustrato intelectual de las reformas que se abrirían a partir de 1765, principalmente los de Ulloa (1740), Campillo (1743), Ward (1762) o Campomanes (1762). Precisamente, esta corriente crítica se había intensificado notablemente durante los años que precedieron a la formación de la Junta Especial, en parte debido también a las excepcionales circunstancias políticas de la Guerra de los Siete Años (1756-1763 $)^{6}$, situando en posiciones de primera fila a esos nuevos burócratas y reformadores que estaban destinados a desempeñar papeles estelares en la nueva política abierta tras la entronización de Carlos III. Aproximadamente desde 1755, venían circulando en las altas esferas de la administración española documentos de naturaleza dispar que ponían el dedo en la llaga de la herida abierta por la debilidad del sistema comercial del imperio español, elaborados por ese conjunto de autores que, como el Marqués de Llanos, Craywinkel, Aragorri u Ortiz de Landázuri, no dudarán en atender la llamada de Esquilache para formar parte de esa Junta Especial. A ese conjunto de documentos pertenecieron unas anónimas y enigmáticas Reflexiones sobre el estado actual del comercio de España.

\section{Las Reflexiones SObRe el estado actual del COMERCIO de ESPAÑa (1761)}

Aunque la existencia de estas Reflexiones fuera conocida desde hace más de dos décadas, hasta la fecha se ignoraba su contenido, debido a la imposibilidad de encontrar un ejemplar de las mismas. A pesar de ello, ninguna duda podía caber acerca de su existencia. De ella había dado cuenta largamente Campomanes, al dedicarle un amplio «Suplemento» en sus Reflexiones sobre el comercio español a Indias, una extensa obra que había venido elaborando

\footnotetext{
${ }^{4}$ Elliott, 2010: 74 y ss.

5 Para una visión más completa, ver Delgado Barrado, 2009: 327 y ss.

${ }^{6}$ Sobre la enorme trascendencia de esa Guerra en el cambio de ritmo en las reformas imperiales, tanto en Gran Bretaña como España, ver Elliott, 2006: 431 y ss.
} 
durante los cuatro primeros meses de 1762 y que finalmente quedó inédita en su época ${ }^{7}$. El inminente Fiscal del Consejo de Castilla abordaba la lectura de esas enigmáticas Reflexiones desde una perspectiva crítica y manteniendo siempre el anonimato de las mismas; y ello a pesar de que la persona que se las había proporcionado, Craywinkel, un próspero comerciante de origen flamenco, bien entroncado con la nobleza catalana, ya le había advertido de que su autor era Simón de Aragorri ${ }^{8}$.

El hallazgo reciente de un ejemplar de esa obra permite ratificar buena parte de los detalles conocidos por vías indirectas acerca de ella. Las Reflexiones sobre el estado actual del comercio de España es un libro fechado en 1761, de casi tres centenares de páginas, en las que se aborda un examen detallado del conjunto de la economía de la Monarquía, su vertiente trasatlántica incluida. Publicado no sólo anónimo, sino también sin referencia editorial y sin apenas paratextos, el libro parecía el resultado final de una elaboración rápida, que pudo extenderse unos seis meses, entre septiembre u octubre de 1760 y febrero o marzo del año posterior, siempre, en cualquier caso, durante la etapa de neutralidad española en la Guerra de los Siete Años. También su impresión parecía apresurada: incluía algunos errores gramaticales y numerosos de naturaleza tipográfica. Por otra parte, con toda probabilidad, su edición hubo de ser financiada por el propio autor. Ello explica que fuera publicado como libro, cuando la mayoría de los documentos de temática similar que circulaban esos años quedaron manuscritos. En cualquier caso, su tirada fue indiscutiblemente reducida: el libro estaba destinado a poseer una circulación restringida y ésa es la razón por la que sus ejemplares sean al día de hoy tan escasos.

Respecto a su autoría, es indudable la certeza del juicio de Craywinkel acerca de su atribución a Aragorri. La razón para defenderlo reside en la milimétrica simetría que existe entre el contenido de las Reflexiones y lo que hoy conocemos -todavía insuficiente- sobre los negocios de su autor cuando acometió la redacción de su obra. Nacido en Hendaya, Simón de Aragorri y Olavide (1725-Madrid, 1806) fue un emblemático representante del grupo de negociantes vascofranceses que supieron aprovechar su condición nativa fronteriza para desarrollar un variado conjunto de negocios, de dimensión internacional, basado esencialmente en la intermediación entre España y, por otro lado, Francia y otros mercados europeos ${ }^{9}$. De un perfil similar al de Cabarrus, comerciante, banquero y financiero a un mismo tiempo, su carrera mercantil transcurrió en sus primeras etapas entre Madrid, donde figuraba

${ }^{7}$ Campomanes, 1762. La obra fue publicada por Llombart en 1988.

8 Tal y como explicó Llombart: Campomanes, 1762: 409, nota 78.

9 Azcona, LIX/3 (Madrid, 1999): 955-987. 
avecindado en los años cincuenta, y Santander, donde en esos años había emplazado su casa de comercio, «Aragorri y hermanos». Desde ella fraguó su primer ascenso en el mundo de los negocios, basado en operaciones con el Real Servicio, operadas como cabeza de negocio o a través de agentes interpuestos. Torres ${ }^{10}$ ha explicado muy bien la pluralidad de estrategias empleadas por Aragorri durante esos años -con suerte dispar, pero a la postre positivapara consolidarse en la red de los grandes asentistas y financieros, españoles y extranjeros, que controlaba los asientos al servicio del ejército y la marina para la provisión de arboladura y tablonería para los arsenales españoles, al igual que de cáñamo, herrajes y todo tipo de provisiones. Para ello, hubo de desplazar a otros asentistas muy consolidados, al tiempo que hubo de crear una densa red de colaboradores, de arraigo internacional, a través de la cual no sólo importaba los bienes requeridos por el Real Servicio, sino que obtenía crédito o explotaba la rentabilidad de la plata que acopiaba a través de ese cuantioso flujo de cambios. De esta manera, a finales de los años cincuenta, Aragorri era uno de los grandes aprovisionadores de la Armada española. Y todo ello, además, sin renunciar a otro tipo de negocios comerciales ${ }^{11}$.

Siguiendo una estructura patrimonial relativamente singular en el caso de España, en razón a «su variedad, su amplitud y su carácter excepcional» ${ }^{12}$, los negocios de Aragorri se ampliaron durante la década de los sesenta a otros dos poderosos ámbitos. El primero fue el comercio de granos: en los años previos al motín de Esquilache, fue nombrado Director del Pósito de Madrid, desde el cual gestionó compras masivas de cereal procedente de Francia, Italia y el norte de África. Con relación al segundo, el comercio colonial, Aragorri tuvo una creciente presencia en él, primero en su faceta de importador mayorista e intermediario de otros comerciantes asentados en Cádiz y Madrid, y después en otros negocios de mayor calado. A ello no fue ajeno el matrimonio que consumó en 1777 con la vizcaína Josefa de la Torre, en lo que supuso la reunión de dos grandes fortunas. La proveniente de su mujer era la propia de un patrimonio más tradicional, mesteño y nobiliario, asentado en la exportación de lana. Esa unión matrimonial le permitió ampliar sus relaciones familiares hacia otros núcleos con notable peso relativo en la Armada y el cuerpo diplomático, tales como Las Casas, O’Reilly, Castaños o Gardoqui, lo cual, a su vez, le

10 Torres, 2006: 710-713.

11 Tales negocios llegaron incluso a implicar al gobierno francés. En 1753 Iranda encabezó una compañía de comercio para la importación de coloniales franceses y su distribución en el mercado europeo; años después, aprovechaba la neutralidad española en la Guerra para actuar como consignatario de buques neutrales destinados al Canadá; ver Delgado, 2007: 214.

12 Zylbeberg, 1993: 136. 
abrió la posibilidad de extender su influencia comercial hacia otros lugares del imperio español, principalmente, a Cuba y Santo Domingo, donde llegará a poseer extensas propiedades, haciendas e ingenios. Así pues, durante los años de elaboración de sus Reflexiones, las operaciones comerciales y financieras descritas permitieron a Aragorri consolidar una fortuna personal más que notable, una de las más cuantiosas de la España de su época ${ }^{13}$. Al mismo tiempo, su ascenso social se veía reconocido a través de la concesión en 1769 de los títulos de Vizconde de Ascubea - pronto cancelado- y de Marqués de Iranda, así como del prestigioso cargo de Ministro Honorario del Consejo de Hacienda.

Así pues, Aragorri supo combinar con gran astucia una próspera actividad mercantil con una inserción no menos incisiva en los círculos del poder político, cuyos primeros pasos están relacionados precisamente con la elaboración de sus Reflexiones. Su contenido pone de relieve que se trató de un escrito original respecto a otros coetáneos sobre el comercio ultramarino, de Llanos, Gossens, Craywinkel, Ward, Campomanes u Ortiz de Landázuri. Al mismo tiempo, aunque las primeras informaciones sobre las Reflexiones ofrecidas por Campomanes hicieron que el libro quedara emplazado entre los versados sobre el problema trasatlántico ${ }^{14}$, en realidad, a lo largo de sus casi tres centenares de páginas, se pasaba revista a todos los principales problemas de la economía española en su conjunto, proponiendo una serie de reformas con una orientación económica muy precisa, muchas de las cuales podían ser activadas con una cierta celeridad. En suma, la obra era un auténtico programa de gobierno para la Monarquía y tenía como principal destinatario ese nuevo poder político, que, según Iranda, poseía entre sus «graves ocupaciones» la de indagar «los diferentes medios de restablecer nuestro comercio». Las Reflexiones fueron elaboradas principalmente para persuadirle sobre la conveniencia de virar desde la herencia intervencionista, proteccionista e industrialista proveniente de los canónicos libros de Uztáriz y Ulloa hacia una estrategia de crecimiento de orientación agrarista y librecambista ${ }^{15}$.

\footnotetext{
industrial.

${ }_{14}$ Diversos autores, además de Llombart, 1992: 132, se han referido en ese sentido a las Reflexiones: Torres, 2006: 709-710. Stein y Stein, 2005: 77. Delgado, 2007: 209-212.

15 Una estrategia de esa naturaleza venía planteándose en España desde los años cuarenta, a raiz de la llegada de la obra de J.-F. Melon. Ver Astigarraga, 2010.
}

${ }^{13} \mathrm{Idem}$. Su enorme fortuna sólo marginalmente se halló relacionada con la producción 


\section{Fuentes de las Reflexiones: Jacques Accarias de Serionne}

Aunque en las Reflexiones se citara recurrentemente a Uztáriz y Ulloa, y de manera ocasional a diversos arbitristas de los siglos previos, la obra carecía en cambio de indicaciones precisas acerca de sus fuentes foráneas. Un análisis de su contenido ha permitido mostrar que en realidad se trató de un plagio, en forma de una traducción-adaptación selectiva. Su fuente principal, aunque no única, era un conjunto de artículos titulado Considérations sur le commerce d'Espagne, que, aunque publicado anónimo, era debido al economista antifisiócrata francés Jacques Accarias de Serionne (Chatillon-enDiois, 1706 - Viena, 1792). Tales artículos vieron la luz entre mayo de 1760 y enero de 1761 en el Journal de commerce (1759-1762) ${ }^{16}$. Serionne había asumido la dirección de esta publicación, considerada la primera europea sobre economía y comercio, poco después de recabar en Bruselas, donde fue editada, huyendo de una situación financiera desastrosa en su Francia natal ${ }^{17}$. En esa ciudad dio inicio a una extensa hoja de servicios para la administración prusiana, que le llevará a residir en Ámsterdam, Viena y Hungría, y a trabajar para dicha administración como periodista, escritor y asesor. De hecho, los artículos plagiados por Iranda eran un extenso informe sobre la economía española, que pocos años después Serionne incluirá en su primer tratado teórico ${ }^{18}$. Su destinatario último era Cobenzl, la principal autoridad de los Países Bajos austriacos entre 1753 y 1770, y bajo cuya tutela política vio la luz el Journal, siempre con la connivencia de la emperatriz María Teresa. De las nueve entregas que comprendían las Considérations sur le commerce d'Espagne, seis fueron traducidas por Iranda y de ellas solo tres se dedicaban a la cuestión trasatlántica ${ }^{19}$.

La deuda contraída por Iranda con Serionne era más intensa respecto a esta cuestión que en todo el resto de su obra. El vascofrancés se limitaba a seguir la narración original, glosándola, matizándola y, más ocasionalmente, introduciendo sus propias censuras. Las más significativas aludían a diversos extractos de cariz político, en los que se explicaba que el contrabando británico permitía financiar tanto «grandes risques» como «frais de corruption»; que las ventajas de los extranjeros en el ultramar se debían, no solo al establecimiento del libre comercio, sino también a «la sagesse et la douceur d'une bonne

16 Sobre el Journal, ver Vercruysse, 1991.

17 Sobre su vida, ver Hasquin, 1974, y sobre su obra económica, Spengler, 1942.

18 Ver «Sur l'Espagne», en Accarias de Serionne, 1766: vol. I, cap. V.

19 Esas tres entregas se publicaron en mayo de 1760: 3-51; junio de 1760: 3-56; y agosto de 1760: 3-33. 
administration»; o que los títulos de propiedad en el Nuevo Mundo sólo se alcanzaban en aquellos territorios donde las naciones se mantuvieran, de ahí que la conquista sólo podía extender esos títulos a ellos ${ }^{20}$. Ahora bien, al mismo tiempo, Iranda omitía valoraciones precisas y citas textuales de Serionne respecto a las fuentes empleadas en sus artículos, incluidas diversas de Uztáriz y Ulloa, seguramente, por resultar familiares para el lector español. Asimismo, la defensa de los intereses de su país y las circunstancias bélicas que rodearon la elaboración de su traducción le llevaron a suprimir expresiones del original que reflejaban una supuesta debilidad de la economía de España, la escasez de trabajos en este país sobre la «ciencia del comercio» o su singular y secular espíritu de «interés y dominación» ${ }^{21}$; al tiempo que exculpaba reiteradamente a los franceses de realizar comercio clandestino en los territorios españoles, lo cual le permitía intensificar sus acusaciones a holandeses y británicos. En este sentido, Iranda omitía los juicios en los que Serionne desconfiaba de la capacidad militar de España para combatir en guerra abierta a los británicos o para reducir su comercio ilícito, a través de guardacostas y el rigor de las leyes. Al margen de otras diferencias de menor relieve ${ }^{22}$, todo ello pone de manifiesto que, como fue habitual en su tiempo, Iranda realizó una traducción fiel de las ideas de Serionne, pero, al mismo tiempo, selectiva y depurada, con el fin de hacerlas afines a las circunstancias bélicas y a las condiciones políticas e intelectuales de la España de ese tiempo.

Aunque las Reflexiones de Aragorri fueron derivadas sustancialmente del trabajo de Serionne, este hallazgo plantea el problema adicional de conocer cuáles fueron las fuentes de este segundo escrito. Ello se debe a la nula atención que ha cosechado la obra de este economista antifisiócrata francés, prácticamente olvidado al día de hoy, a pesar de la enorme fortuna que disfrutó en el siglo XVIII europeo. De hecho, esa obra fue objeto de una difusión notable, alcanzando también a España ${ }^{23}$, de ahí que hubo de desempeñar un

${ }^{20}$ Ver, respectivamente, Journal de commerce, junio de 1760: 22 y 52; y mayo de 1760: 40-41.

${ }^{21}$ Journal de commerce, junio de 1760: 6, 31-32.

${ }^{22}$ Iranda españolizaba los datos sobre las cantidades monetarias, actualizaba las informaciones para acomodarlas a los sucesos de la Guerra, sintetizaba informaciones referidas a las actas de navegación inglesas y a descripciones detalladas sobre los métodos de contrabando empleados por los británicos, omitía extensas descripciones geográficas e históricas, sobre las islas del Caribe, Filipinas y Méjico, y rectificaba informaciones sobre legislación, proyectos y compañías comerciales españolas en Cádiz, Indias y Filipinas, ausentes en el original.

${ }^{23}$ Dos de sus principales tratados fueron traducidos en España por el vizcaíno y alto funcionario de la Hacienda, Domingo de Marcoleta en 1772-1774 y 1774. 
singular papel intermediador en la diseminación de ideas político-económicas contenidas en otros tratados de la economía política de la Ilustración, que Serionne, si bien de forma tácita, utilizó para elaborar los artículos traducidos en las Reflexiones. En su estructura principal, éstas partían de un análisis de la decadencia económica española en la que, se subrayaba, siguiendo principalmente al francés Forbonnais, la relación existente entre ese declive y la errónea administración y política fiscal practicada por los Austrias. A continuación, acometían una explicación de los desórdenes monetarios causados por la afluencia de los metales preciosos americanos en la que era muy perceptible la teoría monetaria de Hume. Con posterioridad, exponían un extenso programa agrarista basado en autores como Herbert o Mirabeau, $y$ en el que Iranda se distanciaba de Serionne al asumir diversas ideas y políticas fisiócratas, en particular el libre comercio exterior de los granos, ausente en sus Considérations. Esta secuencia encontraba su culminación en la segunda parte de la obra, dedicada íntegramente al análisis del sistema de comercio trasatlántico español, documento de notable valía para reconstruir las raíces intelectuales y reformistas de la América hispana en el seno de la historia circunatlántica ${ }^{24}$.

\section{Fundamentos teóricos de las Reflexiones: David Hume}

Aunque inserto en la literatura favorable a la reforma de las relaciones comerciales imperiales elaborada tras la obra de Ulloa ${ }^{25}$, el trabajo de Iranda presentaba sus singularidades: a diferencia de los de Campomanes, Campillo o Ward, se trató de un texto publicado en el momento de su concepción, y frente al de Ulloa, constituyó, como se ha visto, en esencia, un plagio tácito de un trabajo extranjero. A pesar de ello, las Reflexiones también podían ser reconocibles en algunos de los argumentos más característicos utilizados en esa literatura reformadora. Por un lado, al igual, en particular, que el trabajo inédito de Campomanes, en ellas se imbricaba plenamente la reforma del comercio ultramarino en la del conjunto de la Monarquía, lo cual vuelve a incidir, ahora desde el prisma de sus propios protagonistas, en la imposibilidad de tratar por separado las reformas borbónicas metropolitanas y ultramarinas, así como el peso relativo singular de las de contenido económico como un rasgo distintivo de

${ }^{24}$ Armitage, 2002. A su vez, con una notable importancia, desde una perspectiva de la historia global, por el efecto del comercio atlántico en el conjunto intercontinental; ver Canny, 2005.

${ }^{25}$ Ver Stein y Stein, 2000: 217-230. 
ellas $^{26}$. Incluso, como comenzaba a resultar habitual en ese tiempo, los territorios trasatlánticos no eran tratados ya como «reinos de Indias» con una única matriz política cosida por una ley común, sino, más bien, con el expresivo calificativo de «colonias», cada vez más distantes e independientes, así como poseedoras de unas riquezas potenciales más valiosas que las de la metrópoli ${ }^{27}$. En concreto, la propuesta reformadora explicada por Iranda ahondaba en la lógica de la «conservación» de las posesiones del imperio, en vez de en la de su «expansión», si bien, a diferencia de lo que en este plano había venido planteándose desde Campillo, en ellas se ofrecía una defensa sin fisuras de la trascendencia que tenía la implantación con todas sus consecuencias del libre comercio en los territorios del ultramar, para hacer efectiva esa deseada conservación ${ }^{28}$. De hecho, por vez primera en la literatura político-económica española, Aragorri sostenía que, dentro de las limitaciones del «pacto colonial» -la plena subordinación política y económica de esos territorios a la metrópoli-, los principios comerciales que debían regir en el «océano interior» Atlántico debían ser los mismos que en el continente europeo. Se fundamentaban, en suma, en los efectos benéficos que cabía esperar en los planos político (preservación del imperio) y económico (riquezas y bienestar, públicos y privados, a ambos lados del Atlántico) si se sustituía el anacrónico espíritu de «conquista» por el del «dulce comercio» a través de la generalización de la libre competencia ${ }^{29}$. Iranda explicaba reiteradamente que ésta era la principal diferencia respecto a la estrategia adoptada por otros países con colonias, como Gran Bretaña, Francia y Holanda, que habían apostado por la libertad de comercio, con beneficios «notorios» en las riquezas adquiridas; por ello, todo se limitaba a «adaptar sus máximas».

Ahora bien, además de estas experiencias cercanas, la razón de la centralidad que estos principios liberales poseían en las Reflexiones se debió a que fueron derivados, gracias a la intermediación de Serionne, básicamente de los Political Discourses (1752) de David Hume ${ }^{30}$. El punto de partida de Iranda era su idea

26 Ver Elliot, 2001. Paquette, 2008.

${ }^{27}$ En todo ello resuena el eco de la tesis de Montesquieu acerca de que España e Indias eran dos poderes bajo un mismo maestro, pero éstas eran el poder principal y aquélla, el accesorio; Pagden, 1990: 8 y ss.

${ }_{28}$ Pagden, 1995: 110 y ss.

29 Sobre lo que esta cuestión implicaba en España en términos de emergencia de una «nueva política» ilustrada, ver Usoz, 153 (Madrid, 2011): 11-46.

${ }^{30}$ Aragorri hubo de hacer uso de la traducción francesa de la obra de Hume por Jean-Bernard Le Blanc. Encuadrada en la política cultural del círculo de Gournay, su primera edición, de 1754, fue reeditada en Francia y traducida en otros países, incluido, parcialmente, España, en 1789. Aragorri seguía los discursos III, IV y V, dedicados, respectivamente, a «De l'argent», «De l'interêt» y «De la Balance du commerce». Del eco de Hume en España conocíamos el uso que en los años setenta Foronda o Aguirre 
de la existencia de un «orden natural de las cosas» -o bien "curso ordinario de los asuntos humanos» o «general de las cosas»- al cual debían someter los políticos sus decisiones, especialmente las del gobierno económico, si es que, tal y como proclamaban, deseaban alcanzar el bien general. Éste dependía de la concurrencia de una multitud de acontecimientos, así como del azar, y no del capricho o la voluntad de personas concretas. En palabras de Aragorri, las naciones habían participado en las diferentes «revoluciones» históricas -el descubrimiento de América u otras similares- no debido al raciocinio, la voluntad de una nación o la imposición de determinados «principios generales», sino «por casualidad», en función de «su posición, carácter, industria, naturaleza y constitución de su gobierno», de tal manera que «las naciones no pueden vaticinar los acasos; se dirigen según los sucesos ${ }^{31}$. Por este motivo, aunque los políticos lo pretendieran, no resultaba sencillo cambiar ese «orden natural». En la medida en que era necesaria la confluencia de una gran variedad de circunstancias para la culminación de los cambios -Hume sostenía que incluso la opulencia era el resultado de «ciertos accidentes»-, la mejor política era la de acomodarse a la inclinación común del género humano, rectificándola de forma gradual, pero respetando el curso «natural» de las cosas. Aragorri suponía, como Hume, que de esta manera la sociedad comercial alcanzaría un bien general en el que el incremento de la industria y el comercio se armonizaría con el poder del soberano y con la felicidad de los súbditos ${ }^{32}$; en suma, en sus propias palabras, «todas las cosas tienen su curso y sus efectos y se dirigen naturalmente a establecer una utilidad general, que es el principal objeto de la primera ley de las sociedades» ${ }^{33}$.

La existencia de cambios reiterados, causados por factores imprevisibles, era consustancial al mundo del comercio. Éste operaba, por definición, en un marco de incertidumbre, así como sometido a incontables intereses, circunstancias o eventualidades de las sociedades y de la naturaleza, normalmente ajenos al mismo:

Las revoluciones continuas sobre los precios de frutos y ropas, ocasionadas por las vicisitudes de la abundancia y escasez, los caprichos en el gusto de los compradores, la mala fe de los deudores, su imposibilidad de satisfacer sus empeños, los sucesos de guerra o de paz, las plagas con que el cielo castiga de tiempo en tiempo a algún reino, los naufragios, incendios y otras casualidades son accidentes naturales del comercio ${ }^{34}$.

realizaron de sus ideas sobre el lujo y la honorabilidad del comercio; ver Astigarraga, 2003: 126 y ss., 142 y ss.

31 Aragorri, 1761: 21, copia a Hume, 1755: 4-5.

32 Aragorri, 1761: 20-21. Ver Hume, 1755: 4-5 y 15.

33 Aragorri, 1761: 55. Ver Hume, 1755: 15.

34 Aragorri, 1761: 223-224. 
Ahora bien, lo particular de este caso, es que existía un principio económico que hacía que el comercio solventara por sí mismo esos «accidentes naturales». Tal principio era la libertad general de comercio, sustanciada a través de la libre competencia. Así, en una economía organizada en torno a ese principio y ajena a trabas al mismo o a intromisiones por parte de sus responsables públicos, el comercio encontraría por sí solo su «curso natural»:

Los ministros que tienen a su cargo los progresos del comercio ven con indiferencia estos accidentes, que son regulares al comercio, y le dejan volver de por sí a su ser natural, lo que nunca deja de suceder con mucha prontitud. La concurrencia se establece de por sí adonde es necesaria, y se retira lo mismo de donde es nociva ${ }^{35}$.

De esta manera, la libre competencia emergía como la vía principal -si no la única- para que el comercio fuera capaz de sobreponerse a sus propios accidentes «naturales»; lo contrario, es decir, «quererlos prevenir por providencias que estrechen su libertad», era despojarle de los únicos «medios que tiene de recuperarse por la industria y actividad de los comerciantes» ${ }^{36}$. Y, más aún, junto a ello, el ejemplo de las naciones foráneas permitía apreciar cómo la libertad de comercio era el mejor sistema para la emulación y la laboriosidad, así como para lograr que todas las sociedades, incluidas las de los territorios ultramarinos, superaran su tradicional nivel de rusticidad y accedieran al de suntuosidad y refinamiento, con lo que ello suponía en el logro de mayores niveles de bienestar individual:

... he observado y se experimenta que las colonias de las naciones extranjeras van siempre aumentando y floreciendo, lo que depende mucha parte del buen método que han establecido. Hay siempre en América que cultivar y beneficiar. El lujo que introduce el comercio, la facilidad que presenta de conseguir por los productos de las tierras todas las comodidades de la vida son los únicos motivos que animan a aquellos americanos a aumentar sus producciones por su industria. Estas ventajas son los efectos de la libertad de comercio $^{37}$.

Lógicamente, la dimensión de ese «orden natural» al que Iranda, siguiendo fielmente a Hume, aludía era internacional. Ningún país, incluidos los más poderosos, había sido capaz de prosperar -en particular, de edificar su poder manufacturero- en un régimen de independencia comercial. Todos ellos habían tenido que recurrir a un comercio internacional que no era sino la expresión de los «lazos de la sociedad general» en la que sus diferentes partes obtenían beneficios recíprocos a través de él. Esta visión era esencial en la considera-

${ }^{35}$ Ibidem: 163.

36 Ibidem: 223-224.

37 Ibidem: 228-229. 
ción de Hume de que en un mundo comercial la prosperidad de una nación conducía inevitablemente a la de otras y de que, por tanto, el comercio era algo más que un simple cambio de mercancías ${ }^{38}$. Por ello, en palabras de Aragorri, el consumo de cualquier nación debía ser considerado como «el consumo general de los frutos de la industria de toda la Europa y como un bien público en que cada nación participa a proporción de su industria» ${ }^{39}$. Las relaciones económicas internacionales provocaban que disturbios en apariencia menores o localizados en el tiempo o en el espacio afectaran al fluir natural del comercio entre los países. Así, cuando el tráfico de un lugar estratégico, como Cádiz, se ralentizaba, también lo hacía el general, y, de la misma manera, si alguna nación obtenía beneficios comerciales «por medios ilícitos y destructivos», no sólo socavaba los principios generales del «orden natural», sino que ello representaba «un hurto» que se hacía a todas las demás.

Todo esto era especialmente relevante debido a que esos flujos internacionales del comercio determinaban la distribución no sólo del stock de frutos y manufacturas, sino también del numerario y los metales preciosos. En sus finas páginas dedicadas a teoría monetaria, Iranda había aceptado la tesis de Hume de que la afluencia de éstos causaba efectos distintos en la economía receptora, según cual fuera la perspectiva temporal adoptada: a largo plazo, se producía el ajuste automático entre los precios de los bienes y la cantidad absorbida de oro y plata; sin embargo, a corto, antes de que ese ajuste se consumara, las economías nacionales conocían aumentos de los salarios y, por tanto, del lujo y el bienestar, y, con ellos, crecimientos en la economía real, en particular, en la industria, la población y el empleo. Ahora bien, como ya había advertido Hume, la naturaleza de los metales preciosos era similar a la del agua: sin trabas que lo impidieran, se ajustaban automáticamente al nivel de riqueza de las naciones; más en concreto, gravitaban internacionalmente desplazándose hacia aquéllas con un mayor nivel de industria y población: «un país que pierde su comercio, su industria y un gran número de sujetos no puede vanagloriarse de conservar su oro y plata». Por tanto, dado que las fuentes de la riqueza de las naciones eran la población y la industria, el gobierno poseía más razones para estimular éstas que los metales preciosos, pues estos siempre encontrarían el medio de retornar a las naciones más opulentas. Así pues, bien lejos de las rutinas «mercantilistas», las políticas públicas basadas en la consideración de la moneda como un símbolo de la riqueza y en su sobreexplotación estaban condenadas al fracaso.

\footnotetext{
38 Pagden 1995: 179-180.

39 Aragorri, 1761: 158.
} 
Aragorri extraía las principales consecuencias de estos planteamientos. Suponía, como Hume, que no era posible - ni tenía sentido- «conservar en España todo el dinero que los galeones han traído de las Indias» por medio de leyes prohibitivas o el dominio exclusivo de un arte productivo concreto. En realidad, era impensable que España pudiera acumular todos esos metales americanos más allá de su nivel «natural»: el proceso inflacionista en salarios y precios que esa decisión generaría arrumbaría con sus posibilidades de promover la industria nacional. La alternativa lógica era reconocer que la ingente cantidad de metales y frutos provenientes de los territorios americanos, unida al elevado número de consumidores existente en ellos, componían un «fondo inmenso de riquezas» que no era posible retener en España ni «excusarnos de [re]partir con las demás naciones de Europa»; por tanto, convenía «guardar la mayor parte de estos tesoros», pero sabiendo «contenernos en los límites que nos convienen ${ }^{40}$. Frente a Uztáriz y sus seguidores, los metales preciosos eran una parte más de la producción americana que, como sus frutos agrícolas o especias, España debía utilizar para financiar sus importaciones, en particular, esas manufacturas suntuarias cuya producción en términos competitivos quedaba fuera de su alcance y que eran destinadas parcialmente al mercado americano. Por este motivo, como en Hume, convenía mantener una justa proporción entre la cantidad de dinero y el nivel de industria, al ser éste el factor que lograba que el oro y la plata entraran en circulación sin causar desórdenes monetarios. Se trataba, en suma, de alcanzar la cantidad «óptima» de oferta monetaria, tratando al mismo tiempo de que creciera anualmente, aún a costa de soportar una cierta inflación «contenida», dado que ese crecimiento alentaba el espíritu de industria, el fondo de trabajo y las riquezas del pueblo.

Todos esos argumentos desembocaban, lógicamente, en la defensa de la libertad de industria y comercio como eje de cualquier política económica certera. Esa libertad garantizaba la distribución internacional armónica del stock de metales preciosos, conduciéndose estos de una manera «natural»-e insoslayable- hacia las economías más desarrolladas; con ello, se alcanzaría también el equilibrio general de las balanzas de pagos nacionales. Al igual que entre los países europeos, existía también una balanza «respectiva»o «natural» entre Europa y América. Para alcanzarla era necesario sujetar el tráfico trasatlántico a la libre competencia, si bien con una importante mati-

40 Ibidem: 53-54. Conviene recordar que para Iranda el problema monetario no era la única causa de la decadencia española; siguiendo a Forbonnais (1755) subrayaba la importancia de la «mala administración», en particular en el ámbito fiscal. Todo ello incide en la necesidad de una interpretación de esa decadencia que comprenda las dos orillas del Atlántico; ver Elliott, 2002. 
zación: de acuerdo con los principios del pacto colonial, en vez de promover las exportaciones y limitar las importaciones, la norma debía ser «llevar a las colonias la cantidad de frutos y géneros que pueden consumir y traer en retorno todos los que producen». Esto es, los territorios ultramarinos debían tratarse como una parte del comercio interior, para «extraer muchos frutos y géneros de nuestras producciones» e «introducir igualmente las que da la América $\rangle^{41}$. La lógica apuntaba, por tanto, a una estrategia que hiciera efectivo el clásico patrón comercial de intercambio de frutos, materias primas y metales preciosos americanos por manufacturas tanto españolas como, en la lógica de Iranda, también inevitablemente foráneas. El problema se planteaba debido a que el imperio español en las Indias padecía crónicamente de una serie de «causas ajenas»-de «revoluciones» o «accidentes»- distintas a las «naturales», que el libre comercio era incapaz de resolver por sí solo y que impedían que el tráfico realizado en su seno respondiera a ese benéfico «curso ordinario de los asuntos humanos». Bajo estas premisas, Iranda analizaba los que entendía como los dos factores perturbadores más graves del mismo: el contrabando y el monopolio.

\section{El CONTRABANDO, «ACCIDENTE AJENO» AL «CURSO NATURAL» DEL COMERCIO}

El contrabando era presentado en las Reflexiones como un factor clave en la explicación de la secular incapacidad de la Monarquía española para explotar en beneficio propio las riquezas de sus territorios de ultramar: «en este contrabando, tan injusto como insolente, consiste toda la ruina de nuestro comercio de Indias ${ }^{42}$. Iranda sostenía que su extinción era la vía más eficaz para restaurar las postradas posiciones comerciales españolas. Según sus estimaciones, el comercio ilegal crecía año tras año, hasta llegar a duplicarse en los últimos diez ${ }^{43}$; asimismo, estimaba (con Ulloa, en su criterio, el autor español más sagaz en advertir sus nefastos efectos), que podía alcanzar ya la mitad del volumen total del comercio gaditano. En su narración, Aragorri intensificaba el transversal sentimiento antibritánico y pro francés que caracterizaba toda su obra, elaborada, cabe recordar, con el trasfondo siempre

${ }^{41}$ Aragorri, 1761: 217.

42 Ibidem: 178-179.

43 Aragorri parecía suponer que el comercio ilícito se había incrementado notablemente después del asiento de esclavos y la creación de la Compañía del Sur, e intensificado aún más desde la Paz de Aix-La-Chapelle (1748). 
presente de la Guerra de los Siete Años; un sentimiento que sin embargo se entremezclaba, sin pudor, con otro de admiración hacia la eficacia de una estructura imperial definida tradicionalmente en términos más oceánicos que territoriales ${ }^{44}$ y que estaba a punto de consumar su reconocida maestría en los mares, poniendo fin al secular poder imperial francés en Norte América. Los verdaderos culpables de ese comercio ilícito sobre la América española eran los británicos (vía Jamaica, Barbados y otras islas del Caribe) y, en menor medida, los holandeses (vía Curazao o San Eustaquio); en cambio, el realizado por los franceses (vía Santo Domingo) era «muy corto en proporción del comercio libre y legítimo» ${ }^{45}$. Además, junto a su mayor presencia, en el área caribeña, los británicos se distinguían también por la singular crudeza de sus métodos: a la hora de introducir esclavos, manufacturas o pescados en los territorios españoles a cambio de extraer de ellos tabaco, especias, tintes, materias primas y plata, ellos empleaban «una superioridad de fuerzas que hacen recelar una usurpación violenta y tirana» ${ }^{46}$; hasta tal punto era así que protegían ese comercio ilícito con sus propios navíos de guerra y habían fundado «establecimientos» permanentes en las costas de Campeche, Tabasco y Honduras, gracias a los cuales sacaban «inmensas utilidades» de los tintes y las especias locales. Y, precisamente, en lo fructífero de ese comercio ilegal radicaba la razón de que, hasta esa fecha, la próspera Jamaica fuera una mera «mina de plata», un «entrepot trade» más interesado en el gasto suntuario que en desarrollar el cultivo de la caña de azúcar, tabaco y otros frutos similares ${ }^{47}$.

Para Iranda este dominio británico sobre los territorios españoles generaba «una revolución cuya causa es permanente». Y, abortada la vía de la restitución de ese comercio a su «flujo regular» a través de medios «naturales», se imponía la de la mediación política. Al tratarse de una cuestión con implicaciones sobre el conjunto del comercio europeo, Iranda apelaba a los intereses comerciales de éste para, a través de un pacto multilateral, protegerse conjuntamente de la insaciable voracidad de los británicos. Ésta parecía la respuesta política más adecuada, dado que estos se desentendían de todas las leyes «naturales» y recíprocas que fundamentaban el comercio internacional, según las cuales «ningún extranjero puede comerciar con ellas [las colonias extranjeras] directa o indirectamente». En efecto, el problema era que Gran Bretaña desobedecía intencionadamente las normas jurídicas más elementales del Derecho natural, así como las de su Derecho positivo, las cuales, tratándose, como era el

\footnotetext{
44 Armitage, 2000: 195 y ss.

45 Aragorri, 1761: 181.

46 Ibidem: 172.

47 Zahedieh, 2002: 63-64.
} 
caso, del comercio interior de un país, le obligaban a contenerse en el límite de sus posesiones. Por ello, ante la insuficiencia de las medidas defensivas tradicionales adoptadas por España (guardacostas, asientos, etc.), era acuciante la exigencia a Gran Bretaña del respeto a una nueva ley internacional que, bajo el manto de la «causa pública», prohibiera esas prácticas clandestinas o las castigara con rigor.

Ahora bien, Iranda era muy consciente de las escasas posibilidades de que se abriera paso la vía de la negociación política, más aún cuando sus Reflexiones se elaboraron en plena Guerra de los Siete Años; por ello, barajaba otras soluciones distintas, que, de una u otra manera, habitaban en el linde de la pura guerra comercial. La primera era practicar la reciprocidad respecto a las Actas de Navegación británicas (1651 y 1660). En su opinión, éstas habían sustanciado una ley «no menos injusta que temeraria», diseñada inicialmente para preservar el comercio colonial para los ciudadanos del Imperio, excluyendo de él -con pleno éxito- al comercio intermediario holandés. No obstante, a la larga, esas Actas habían terminado por imponer un «yugo tirano al comercio general», tanto al europeo como al trasatlántico, hasta el punto de que buena parte del creciente dominio por parte de Gran Bretaña -incluido el realizado por vías ilícitas- era atribuible a ellas $^{48}$. En una estrategia aún más radical, Iranda apelaba a la posibilidad de suspender el comercio de España con Gran Bretaña, llevando así hasta sus últimas consecuencias el sustrato de unos pactos borbónicos que venían inclinando gradualmente el comercio español hacia Francia, en detrimento de Gran Bretaña, con el consiguiente perjuicio de ésta en su dominio de un mercado cautivo, como era el hispano, en el que le resultaba simple colocar sus manufacturas, muchas de las cuales eran después remitidas desde Cádiz a Indias, a cambio de extraer de él frutos, materias primas y, sobre todo, metales preciosos ${ }^{49}$.

Ahora bien, la terca realidad se imponía y obligaba a Iranda a retornar desde el terreno hipotético al real. Junto a sus lamentaciones por la hábil manera en que Gran Bretaña anudaba capacidad comercial y militar para imponer un

48 Aragorri, 1761: 186-190, traducía en su obra algunos de los artículos de esas famosas Actas.

49 En esta línea, es muy ilustrativo el uso por Aragorri, 1761: 180-181, siguiendo a Serionne, de los escritos incluidos en The Bristish Merchant, debido a Charles King y traducido en Francia por Forbonnais (1753). Dichos escritos atacaban el panfletismo librecambista de finales del siglo XVII y salían en defensa de los intereses manufactureros británicos a través de políticas proteccionista respecto a Francia; ver Jonson, 1937: 141157. Appleby, 1978: 120 y ss., 248 y ss. Según Aragorri, esta «imaginaria y artificiosa declamación contra Francia» nunca podía justificar la estrategia comercial agresiva británica. 
contrabando que no era sino el «monopolio más nocivo, destructivo y odioso que se puede hacer sobre nuestro comercio» ${ }^{50}$, el vascofrancés asumía con toda su crudeza también que ese comercio ilícito no se debía únicamente a la avidez británica. Era también una consecuencia directa de la pésima gestión económica del imperio español: Iranda estimaba que solo uno de cada quince pesos importados desde las Indias era español, de manera, que en él operaba una conciencia muy lúcida de que la América hispánica era en términos prácticos «extranjera». Se había convertido en un virtual condominio defendido y administrado desde España pero explotado por las naciones europeas ${ }^{51}$. Por ello, parecía particularmente pertinente focalizar el estudio de las posibles soluciones en un análisis crítico del sistema comercial trasatlántico vigente. Y, abortada en términos prácticos la vía negociadora con Gran Bretaña, se imponía otro camino alternativo, en cualquier caso, más «seguro» y «eficaz»: oponer la introducción «legítima a la ilegítima», favoreciendo por medio del libre comercio una mayor presencia de los bienes españoles en las Indias. Se trataba de un aggiornamento de esa vieja política, de sustrato británico, de anudar las reformas con el comercio, bien apreciada ya desde Campillo, pero que ahora resultaba más necesaria aún, dada la importancia de poseer un sistema comercial más eficiente y competitivo de cara, no sólo a minimizar los daños que ya estaba causando la omnipresencia británica en el imperio español, cuanto a edificar esa fuerza militar estable y más gravosa a la que obligaba la Guerra de los Siete Años y el nuevo equilibrio territorial que, con toda certeza, se iba a derivar de ella ${ }^{52}$.

\section{LA LIBERTAD DE COMERCIO COMO LA AUTÉNTICA SOLUCIÓN}

Para Iranda, la existencia del contrabando -amén de prácticas poco honrosas, como el soborno a funcionarios- se debía en última instancia a las características singulares de los mercados trasatlánticos, bien estrechos, estancados y fiscalmente sobrecargados, o bien explotados a través de compañías privilegiadas. Respecto a éstas ${ }^{53}$, entendía que representaban una pésima alternativa para ejercer el comercio ultramarino, pues operaban a base de reducir

50 Aragorri, 1761: 175.

${ }^{51}$ De acuerdo con la expresión de Pagden, 1987: 92.

52 Elliott 2006: 435 y ss. Aunque en las fechas en que las Reflexiones fueron elaboradas, no se había consumado aún la traumática toma de La Habana por los británicos, estos ya aparecían como los virtuales vencedores del conflicto bélico: en la obra se mencionaba la caída en sus manos del Golfo de San Lorenzo y Canadá.

${ }_{53}$ Sobre esta cuestión, ver Delgado Barrado 2007, 153 y ss.; 2009, 177 y ss. 
el tráfico y elevar artificialmente los precios, institucionalizando por tanto un sistema monopolista casi «más perjudicial que la tolerancia del mismo contrabando». Por ello, y aun sin mencionar las compañías entonces vigentes (Guipuzcoana, La Habana y Barcelona), en las Reflexiones se elogiaba la decisión de las autoridades españolas de haber renunciado a canalizar ese comercio exclusivamente a través de este tipo de empresas. Si, en este punto, Iranda se distanciaba de autores como Marcenado o Zavala y era más afín a Uztáriz o Ulloa, en cambio, arremetía contra todos ellos cuando valoraba la incapacidad de España para apostar decididamente por la «libertad general de comercio». Ésta era presentada por él como el único medio que podía arrumbar el contrabando y al mismo tiempo explotar las riquezas americanas en beneficio de la Monarquía. El efecto combinado del sistema de puerto único, flotas, alta fiscalidad y enrevesadas regulaciones incentivaba crónicamente el contrabando y convertía en acuciante la reforma del comercio ultramarino: «la causa del abandono tan grande del comercio de nuestras islas no consiste en otra cosa sino en el método establecido para el comercio de Indias, y subsistirá mientras no se permita la libertad general del comercio» ${ }^{54}$.

En efecto, para Iranda, el marco regulador vigente era inmejorable para el ejercicio de operaciones ilícitas, dado que, al extremar el diferencial de precios colonias-metrópoli, incentivaba la obtención de beneficios extraordinarios. La única manera de solventar ese problema era configurar otro marco que, basado en la libre competencia, limara de forma natural esos beneficios extraordinarios. Iranda, tal y como había hecho en otros pasajes de su obra al analizar el mercado del grano, se extendía largamente sobre los efectos positivos de ese sistema de cara a la mejora de la gestión económica de las Indias. En primer lugar, la libre competencia resolvía los problemas de información derivados de la estructura de los mercados vigentes: dado que los contrabandistas actuaban con más rapidez que la Administración, el comercio ilícito provocaba que la información manejada por ésta fuera falsa; por ello, era difícil que la toma de decisiones públicas respondiera a las necesidades reales de abastecimiento de los mercados ultramarinos. Asimismo, en segundo lugar, un sistema competitivo soslayaba las situaciones extremas de abundancia y escasez de las mercancías españolas en ellos y además favorecía el abaratamiento de sus precios, mejorando su competitividad respecto a las extranjeras, incluso respecto a las traficadas a través de sus poderosas compañías de comercio; y, como efecto de ello, también pondría fin a esas operaciones comerciales que, llamadas por las altas rentabilidades, atraían el contrabando extranjero, generando incentivos para otras que constituían la base «más sólida» del comercio

${ }^{54}$ Aragorri, 1761: 94-95.

Revista de Indias, 2013, vol. LXXIII, n. ${ }^{\circ} 259,759-788$, ISSN: 0034-8341 doi:10.3989/revindias.2013.25 
ultramarino español. Éstas eran las realizadas de manera ágil para responder a los requerimientos de la información, en navíos de bajo porte, a través de un tráfico más continuado y que remuneraran al capital con beneficios menores o, en sus palabras, «normales»: en suma, el negociante debía «ganar poco», pero de forma continuada ${ }^{55}$. Complementariamente, con el fin de enfrentar de manera directa el mercado ilegal, proponía el establecimiento de almacenes, con bienes a precios competitivos, en aquellos pasajes costeros frecuentados por los contrabandistas. En realidad, Iranda presentaba la «libertad general de comercio» como la única vía para restituir el comercio a ese «curso ordinario» del cual había sido despojado debido a la existencia de un «accidente» tan poderoso como el contrabando crónico.

Así pues, todas estas ideas abonaban un cambio en profundidad del sistema de comercio trasatlántico, y nada extraña que el dedo crítico de Iranda apuntara a Ulloa si tenemos presente que, como es conocido, los programas modernizadores de Campillo-Ward y Campomanes circulaban entonces inéditos. Al vascofrancés no le convencía la supuesta vía intermedia planteada por Ulloa entre el sistema de compañías privilegiadas y el libre comercio; por ello, tras acusarle de no ofrecer «ninguna razón de fundamento» contraria a este segundo, abogaba por una liberalización de marco regulador vigente más radical que la defendida por él, así como por quienes le habían precedido: conviene recordar que el andaluz se había mostrado partidario del monopolio gaditano; Zavala o Marcenado, de las compañías de comercio privilegiadas; y Uztáriz, del sistema de tropas y galeones. A diferencia de ellos, Arragorri planteaba abiertamente que era preciso «desengañarnos sobre el método que hasta ahora se ha seguido, de limitar el número de navíos, toneladas, géneros, etc. ${ }^{56}$ En realidad, él sostenía que una vez que en España se había tenido conciencia de la magnitud del problema del contrabando, se debía de haber abrazado de manera inmediata un sistema de libre comercio similar al que venía extiendo su influencia, tanto doctrinaria como práctica, desde la Gran Bretaña de finales del siglo XVII ${ }^{57}$. Si ello no había sido así, era debido a

55 Esta estrategia comercial de precios bajos, beneficios reducidos y operaciones de tráfico multiplicadas, como garantía de las posibilidades de un mayor consumo basado en la expansión del mercado, cuajó entre los economistas británicos del finales del siglo XVII; ver Appleby, 1987: 112-115.

56 Aragorri, 1761: 207. Las muy tímidas reformas desarrolladas en las décadas previas a la elaboración de las Reflexiones se sistematizan en Walker, 1979. También Fisher, 1985: cap. 1.

57 En vez, por tanto, de «enrocarse» y de atrasar la puesta en marcha de reformas evidentes a la luz de la experiencia foránea, y todo ello sin tomar en consideración la dimensión política de las reformas en Gran Bretaña; ver Bernal, 2005: 520 y 522. En 
rutinas poco justificadas: ese sistema «no tiene contra sí mas que la oposición de la costumbre que hasta ahora se ha practicado», y entre ellas resaltaba la resistencia a considerar los metales americanos como un fruto natural más que debía de utilizarse para compensar la deficitaria balanza de pagos española.

En la concreción de su sistema de libertad de comercio, Aragorri volvía sus ojos a las reformas desarrolladas por las potencias extranjeras. El reto era, en suma, «aprender del enemigo» ${ }^{58}$, esto es, adaptar esas beneficiosas prácticas comerciales foráneas, siempre dentro de la lógica del pacto colonial. El ejemplo de Francia, principal competidora comercial y militar de Gran Bretaña y con una estructura política, económica y religiosa más cercana a la española, era lógicamente el más útil. A diferencia de España, la metrópoli francesa se abastecía de materias primas y especias producidas en sus islas caribeñas, gracias a la notable expansión en ellas del cultivo; mientras, la consiguiente eclosión en esos territorios de una nueva y fortalecida demanda los había transformado en «el mayor mercado o feria para la salida y consumo de todos los géneros». A través de una estrategia similar, España podría garantizar que el patrón comercial intrínseco al pacto colonial, basado en el intercambio de metales y frutos americanos por manufacturas españolas, dejara de ser un monopolio teórico para pasar a ser efectivo. Para ello en los territorios ultramarinos se debía estimular un auténtico programa de desarrollo de su agricultura y su población, al tiempo que ésta obtenía «de los dominios de su soberano todo lo que necesita para sus consumos». Por ello había que combatir esas florecientes -y ya seculares- manufacturas de textiles, aguardientes y otros bienes que habían aflorado en suelo americano, en particular, en Nueva España ${ }^{59}$, bien prohibiéndolas o bien recargándolas con tipos impositivos que convirtieran en competitivas a las peninsulares.

\section{Un «NUEVO SISTEMA» PARA EL COMERCIO TRASATLÁNTICO ESPAÑOL}

Asentados los principios de su propuesta de reforma, Iranda exponía un ilustrativo reglamento de quince artículos en el que detallaba las condiciones precisas de la misma ${ }^{60}$. Esto era una muestra más de que sus Reflexiones

efecto, en este país dominaba la idea del free-trade, dentro del armazón de las Actas de Navegación, desde finales del seiscientos. En la difusión en Francia de su política colonial tuvo una gran responsabilidad el grupo de Gournay, en particular, Butel-Dumont, autor de dos libros profusamente empleados por Serionne en sus artículos; ver Butel-Dumont 1755; 1757. El primero de ellos será traducido en España en 1768.

58 En acertada expresión de Elliott, 2009: 25 y ss.

59 Pagden, 1987: 91 y ss.

${ }^{60}$ Aragorri, 1761: 250-253. 
poseían una dimensión política indiscutible, al tratar de incidir sin tapujos en el debate en curso sobre el estado del comercio español; de hecho, ese reglamento no figuraba en el texto original de Serionne. Aragorri partía, de acuerdo con el ejemplo foráneo, de la reducción o la supresión de los impuestos trasatlánticos. Esas tasas excesivas, en forma de derechos de palmeo o toneladas, además de encarecer ingentemente los fletes, permitían a los contrabandistas disfrutar de un precio de las mercancías puestas en Indias un tercio menor que las españolas, lo cual era una auténtica garantía para su competitividad. Además, la reducción de la presión fiscal, lejos de suponer una minoración de los ingresos de la Hacienda, estimularía su crecimiento, debido al aumento de la actividad comercial y la reducción del contrabando: Aragorri estimaba que cada millón de pesos obtenido a través de impuestos sobre el comercio a las Indias incentivaba operaciones fraudulentas por un valor seis o siete veces mayor. Su propuesta fiscal se concretaba en la libertad de derechos para los géneros españoles exportados a Indias y el pago riguroso del $10 \%$ de los extranjeros. En el tráfico inverso, se abogaba por una política selectiva de derechos, con el fin de promover los bienes necesarios para el consumo interior y las industrias metropolitanas, además del ya mencionado recargo fiscal sobre las manufacturas americanas.

Asimismo, la política liberalizadora exigía, lógicamente, la disolución del estanco de Cádiz y de su Casa de Contratación, instaurando de manera inmediata y general la libertad de puertos. El comercio ultramarino debía abrirse a «cualquier puerto de la península para cualquier paraje de la América», siempre y cuando aquéllos dispusieran de aduanas. No obstante, incluso en el caso de los de Bilbao y San Sebastián, que carecían de ellas, se articulaban medidas complementarias para su habilitación -en esencia, cumplir los procedimientos aduaneros vigentes en la Compañía de Caracas-. Esta libertad de puertos se presentaba unida a la disolución en todo el espacio trasatlántico del sistema de flotas y galeones y a su sustitución por el de navíos sueltos, con libertad en todo el espacio imperial, tanto de puertos de salida y de llegada como de tránsito y de comercio. El tráfico de los comerciantes privados debía realizarse en buques pequeños, a través de viajes «breves» y frecuentes, remunerados con beneficios moderados, y, salvo condiciones muy precisas, como en las Actas británicas, en navíos españoles regidos mayoritariamente por nacionales. En ese contexto, aunque pudiera darse el caso de la quiebra de algunos negocios privados, demasiado «imprudentes o codiciosos», ello no afectaría al conjunto del comercio ultramarino, que no dejaría de ampliarse, al tiempo que la Monarquía se enriquecía.

Así las cosas, el comercio ultramarino debía dejar de pivotar sobre Cádiz, un puerto caro e inadecuado desde el punto de vista de los intereses defensivos 
españoles. Su liberalización generaría beneficios a todas las regiones españolas, cantábricas y mediterráneas, y así lo ponía de relieve un primer balance de Aragorri sobre las posibilidades económicas que se abrirían en ellas. Pero lo mismo podía afirmarse de los territorios de ultramar. Esa reforma era considerada la pieza clave para lograr reconducir ese perfil colonial español tan singular, ligado a un crecimiento focalizado erróneamente en el monocultivo del oro y la plata, hacia otro que abarcara un auténtico programa de desarrollo de la población y la agricultura americanas ${ }^{61}$, especialmente de esta segunda, la auténtica fuente de las riquezas. Aragorri pensaba en particular en la promoción de los «granos, sedas, lanas, vinos, aceites, azúcares» americanos, así como de determinadas especias allí cultivadas, ahora importadas desde Europa (pimienta, canela, clavo o azúcar), tal y como hacían los franceses ${ }^{62}$.

Así pues, él se ratificaba en que el sistema imperial español disponía de las mejores condiciones para garantizar frutos y metales preciosos que permitieran, primero, y ante todo, seguir sosteniendo a la Monarquía y su imperio -la tax machinery dedicada a extraer remesas monetarias desde la estratégica Nueva España, lejos de perder vigor, se intensificó en las últimas cuatro décadas del régimen colonial ${ }^{63}-$, y después fundamentar el desarrollo metropolitano. Enfrentado al legado económico industrialista, intervencionista y proteccionista proveniente de Uztáriz y Ulloa, la pieza clave de su estrategia de crecimiento era un programa agrarista y liberal, sustentado en el libre comercio interior y exterior de los granos y frutos agrarios españoles. El vascofrancés sumaba a los beneficios derivados de este sector agrícola modernizado, los provenientes de los frutos americanos, destinados tanto a su reexportación a Europa como al abastecimiento del mercado metropolitano y su industria. España dispondría con todos ellos de recursos suficientes para, por un lado, financiar ese modesto sector industrial de textiles bastos y bienes agroalimentarios (harinas, aguardientes, etc.), los únicos que podía colocar en un mercado poco competitivo como era el de sus territorios americanos, y, por otro, importar esas manufacturas suntuarias europeas que ella no podía

${ }^{61}$ Bernal, 2005: 196 y 236 y ss.

${ }^{62}$ El modelo francés guiaba también las sugerencias de Aragorri sobre el tráfico de esclavos. Así, proponía establecer la libertad de comercio en las costas de África para su compra y su conducción a América, concediéndoles la libertad de derechos en los géneros que llevasen para este tráfico y una gratificación por cada esclavo introducido, en vez de, como era la situación vigente, tener que pagar derechos reales por ello. Gracias a ese sistema las islas francesas consumían veinte mil negros cada año, con importantes rendimientos productivos; Aragorri, 1761: 97-98.

${ }_{63}$ Tal y como explica con detalle Marichal, XV/3 (Madrid, 1997): 475-505; 1999: $52 \mathrm{y}$ ss. 
producir en condiciones competitivas y que, además, tampoco era conveniente que lo hiciera, pues su compra con cargo a las remesas metálicas trasatlánticas constituía la mejor vía para soslayar los desórdenes monetarios generados por éstas. Por último, todo ello beneficiaría también al conjunto del comercio europeo: la competencia abarataría el precio de los frutos americanos y, con ello, se iría estableciendo esa balanza de comercio de las naciones europeas con América ajustada a su «curso natural», ahora desvirtuada por la acción del contrabando y el monopolio.

Iranda establecía una única excepción a este régimen generalizado de libertad de comercio: la creación de una compañía privilegiada para la navegación directa desde Cádiz a Filipinas. En realidad, respecto a esta cuestión, él no sólo daba satisfacción a una demanda muy reiterada en el pensamiento reformista español, sino que volvía su mirada a diferentes iniciativas empresariales -si bien sin plasmación definitiva- ya planteadas desde 1733, así como a un proyecto planteado por Ulloa en términos muy similares a los utilizados por él ${ }^{64}$. La compañía que se propone en las Reflexiones estaba destinada a sustituir el monopolio vigente realizado por el Galeón de Manila $-\mathrm{o}$ Nao de China-, que desde finales del siglo XVI unía anualmente el archipiélago filipino con Nueva España a través de Acapulco, intercambiando remesas de plata por bienes asiáticos ${ }^{65}$ : «el yerro que hemos cometido en punto al comercio de Indias Orientales es haber prohibido el comercio directo, que nos conviene hacer, y permitido el de Filipinas a Acapulco, que debíamos haber prohibido con el mayor rigor» ${ }^{66}$. La recomendación de Iranda es que esa nueva empresa comercial conectara España con Filipinas a través del Cabo de Hornos o el Estrecho de Magallanes, y no Acapulco. Una segunda compañía habría de encargarse del tráfico de las mercancías que llegasen a esta ciudad mejicana desde Filipinas, trayéndolas después a Cádiz.

En suma, en las Reflexiones de Iranda el sistema imperial español debía acomodarse a un programa de liberalización plena y a través de un acto de reforma único de su comercio interior. Al mismo tiempo, éste habría de disfrutar de una leve protección respecto a la competencia exterior: una vez reformado el sistema fiscal español en la línea planteada por Aragorri, la tasa arancelaria quedaría fijada en el $10 \%$. Se trataba, en su conjunto, de una propuesta de

${ }^{64}$ Ulloa 1740: vol. I, cap. VII.

${ }^{65}$ Díez-Trechuelo, 1965: 5-9. Martínez-Shaw, 2007. Iranda tendrá una participación decisiva, junto a Bernardo Iriarte, en la fundación de la Compañía de Filipinas en 1785, un cuarto de siglo después de escribir sus Reflexiones. En éstas, abogaba también por instaurar un navío anual directo hacia Campeche con el fin de extraer su palo de tinte y frenar la incesante expansión británica allí.

${ }_{66}$ Aragorri, 1761: 265. 
sustrato liberal más audaz que las de Ulloa y Campillo-Ward, o la que Craywinkel elaborará dos años después de las Reflexiones ${ }^{67}$. En cualquier caso, su influencia inmediata en la reforma del comercio trasatlántico emprendida poco después desde las más altas instancias de la Monarquía parece que fue más bien escasa. Aunque pudieran hallarse rastros de las Reflexiones en el extenso documento elaborado por la Junta Especial que formalizó Esquilache en julio de 1764 para promover esa reforma -en la que participó personalmente el propio Aragorri- ${ }^{68}$, sus recomendaciones eran más moderadas que las defendidas por Aragorri en su libro. Y esto mismo puede afirmarse, y con más rotundidad aún, respecto al articulado definitivo del primer Reglamento del comercio libre de 1765. Éste, concebido en buena medida para dar solución a la crisis política originada por la traumática toma por los británicos de La Habana, recogió sólo parcialmente los consejos planteados por esa Junta Especial: extendió el ámbito del comercio libre sólo a nueve puertos peninsulares, así como a Cuba y otras islas del Caribe, en el seno de un marco tributario nuevo ${ }^{69}$. Por tanto, cabe pensar que, lejos de un efecto inmediato, el de las Reflexiones fue un efecto de largo alcance y que la larga sombra de su influencia pudo dejarse notar en las etapas posteriores del desarrollo gradual que seguirá el programa del comercio libre, en particular a través de los Reglamentos de 1778 y 1789 que ampliarán el área del comercio libre a numerosos puertos peninsulares y a todo el espacio ultramarino español, terminando así de materializar ese marco de libertad de comercio interior en el seno de un armazón proteccionista que había sido defendido en ellas ${ }^{70}$.

\footnotetext{
${ }^{67}$ Sus prevenciones a disolver plenamente al estanco de Cádiz se explican en el manuscrito de Craywinkel de 1763: 18-20, Discurso sobre si conviene o no abrir indistintamente y sin limitaciones todos los puertos de España al comercio de Indias, depositado en la Fundación Universitaria Española, Madrid.

${ }^{68}$ Algún rastro de las Reflexiones puede hallarse en las partes iniciales de ese documento, que afrontan las causas de la decadencia española; Consulta hecha a su Magestad... APR, II/2639, folios 1-17.

69 Sobre esta cuestión, ver Fisher, 1997: 134 y ss. Stein y Stein, 2005: 83-95. Delgado, 2007: 209 y ss. Respecto a sus diferencias de fondo con la estrategia imperial británica, ver Elliott, 2006: 443 y ss.

${ }^{70}$ De hecho, según Flórez Estrada, fueron Iranda y Campomanes quienes persuadieron a Gálvez, Ministro de Indias, para que desarrollara el crucial Reglamento de 1778; Stein y Stein, 2005: 413, nota 78. Una valoración de sus resultados desde la óptica de la influyente plaza gaditana, se encuentra en García-Baquero, 1998: 43 y ss.
} 


\section{Conclusiones}

Esta primera revisión del contenido referido al comercio ultramarino presente en las, hasta ahora, enigmáticas Reflexiones sobre el estado actual del comercio de España (1761), de Simón de Aragorri, Marqués de Iranda, pone de manifiesto el notable y peculiar interés de ese contenido. Aragorri, de manera tácita, realizaba en su libro una traducción selectiva de las ideas del economista francés Accarias de Serionne, muy influidas a su vez por las del escocés Hume, y las aplicaba a la realidad española. Tales ideas quedaban plasmadas en un preciso programa de reforma para el comercio trasatlántico español. Su finalidad era incidir en el debate político abierto en los prolegómenos de la elaboración del primer Reglamento del comercio libre de 1765 a través de una propuesta profundamente liberal y, debido a ello, bastante singular respecto al resto de la publicística de contenido económico que circulaba durante esos años entre las elites políticas españolas. El énfasis de Aragorri se ponía en las virtudes esenciales del «comercio», y más en particular de la libre competencia, como medio para coser las relaciones entre la metrópoli y sus territorios de ultramar. Y aunque sus Reflexiones soslayaran las derivaciones de naturaleza política que en última instancia implicaba la aceptación de los principios de la sociedad comercial, tal y como resultaba ya evidente en Gran Bretaña o Francia; en cambio, manifestaban una convicción profunda de que la manera de amortiguar la incipiente deriva hacia la «independencia» de los territorios del ultramar detectada en un relevante documento oficial elaborado en 1765 era emplear una estrategia de libertad de comercio interior en el seno de un armazón proteccionista para anudar una fructífera «dependencia» de los mismos hacia su metrópoli, algo que el lento y gradual desarrollo del programa de comercio libre pondrá una y otra vez en evidencia.

\section{BiBLIOGRAFÍA}

Accarias de Serionne, Jacques, Les intérêts des nations de l'Europe, développés relativement au commerce, Leide, Elie Luzac, 1766.

Appleby, Joyce Oldham, Economic Thought and Ideology in Seventeenth-century England, Princeton, Princeton University Press, 1978.

[Aragorri, Simón de], Reflexiones sobre el estado actual de el comercio de España, s. 1., s. e., 1761.

Armitage, David, The Ideological Origins of the British Empire, Cambridge, Cambridge University Press, 2000. 
Armitage, David, “Three Concepts of Atlantic History”, D. Armitage y M. J. Braddick (eds.), The British Atlantic World, 1500-1800, New York, Palgrave MacMillan, 2002: 11-27.

Astigarraga, Jesús, Los ilustrados vascos, Barcelona, Crítica, 2003.

Astigarraga, Jesús, "La dérangeante découverte de l'autre: les (més)aventures de l'Essai politique sur le commerce (1734) de Jean-François Melon dans l'Espagne du XVIIIe siècle", Revue d'Histoire Moderne et Contemporaine, 57/1 (París, 2010): 91-118.

Astigarraga, Jesús, Las "Reflexiones sobre el estado del comercio de España” (1761) de Simón de Aragorri. Contenido, estudio de fuentes y primera interpretación, Madrid, AEHE, Documento de Trabajo no 1109, 2011.

Azcona, Ana Mercedes, "La presencia de la minoría bayonesa en la dinámica del comercio franco-español del siglo XVIII”, Hispania, LIX/3 (Madrid, 1999): 955-987.

Bernal, Antonio Miguel, España proyecto inacabado, Madrid, Marcial Pons, 2005.

Butel-Dumont, Georges-Marie, Histoire et commerce des colonies angloises dans l'Amérique septentrionale, Londres, 1755.

Butel-Dumont, Georges-Marie, Histoire et commerce des Antilles angloises, s. 1., 1757.

Campillo, José del, Nuevo sistema de gobierno económico para la América (1743), Madrid, Imprenta de Cano, 1789.

Campomanes, Pedro Rodríguez de, Reflexiones sobre el comercio español a Indias (1762), V. Llombart (ed.), Madrid, IEF, 1988.

Canny, Nicolas, "Atlantic History and Global History”, R. Pieper y P. Schmidt (eds.), Latin America and the Atlantic World, Köln, Böhlan, 2005: 25-34.

Delgado, Joseph María, Dinámicas imperiales (1650-1796), Barcelona, Bellaterra, 2007.

Delgado Barrado, José Miguel, Aquiles y teseos. Bosquejos del reformismo borbónico (1701-1759), Granada, Universidades de Granada y Jaén, 2007.

Delgado Barrado, José Miguel, Quimeras de la Ilustración (1701-1808), Castelló de la Plana, Universitat Jaime I, 2009.

Díez-Techuelo, María Lourdes, La Real Compañía de Filipinas, Sevilla, Escuela de Estudios Hispano-Americanos de Sevilla, 1965.

Echabas, Margaret, "Temporal Dimensions in Hume's Monetary Theory", C. Wennerlind y M. Schabas (eds.), David Hume's Political Economy, London and New York, Routledge, 2008: 127-145.

Elliott, John H., En búsqueda de la Historia Atlántica, Las Palmas, Cabildo de Gran Canaria, 2001. 
Elliott, John H., “América y el problema de la decadencia española”, J. H. Elliott, España en Europa, Valencia, Universitat de València, 2002: 217-236.

Elliott, John H., Imperios del mundo atlántico. España y Gran Bretaña en América (1492-1830), Madrid, Taurus, 2006.

Elliott, John H., España, Europa y el mundo de Ultramar, 1500-1800, Madrid, Taurus, 2010.

Fisher, John, Commercial relations between Spain and Spanish America in the Era of Free Trade, 1778-1796, Liverpool, University of Liverpool Press, 1985.

Fisher, John, The Economic Aspects of Spanish Imperalism in America, 1492-1810, Liverpool, Liverpool University Press, 1997.

García-Baquero, Antonio, Cádiz y el Atlántico (171-1778), Sevilla, CSIC, EEHA, 1976.

García-Baquero, Antonio, El libre comercio a examen gaditano, Cádiz, Universidad de Cádiz, 1998.

Forbonnais, François Véron de, Le négociant anglois, Paris, Estienne, 1753.

Forbonnais, François Véron de, Considérations sur les finances d'Espagne, 2a ed., Dresde-Paris, 1755.

Hasquin, Hervé, "Jacques Accarias de Serionne, économiste et publiciste français au service des Pays-Bas Autrichiens", R. Mortier y H. Hasquin (eds.), Études sur le XVIIIe siécle, Bruxelles, Université de Bruxelles, 1974: 159-170.

Hume, David, Discours Politiques, traduits de l'anglois de Monsieur Hume, Dresde, Michel Groell, 1755.

Johnson, E. A. J., Predecessors of Adam Smith, London, 1937.

Journal de commerce, Bruxelles, J. Van den Berhen y P. de Bast, 1759-1762.

Llombart, Vicent, "Estudio Preliminar", P. Rodríguez de Campomanes, Reflexiones sobre el comercio español a Indias (1762), Madrid, IEF, 1988.

Llombart, Vicent, Campomanes, economista de Carlos III, Madrid, Alianza, 1992.

Marichal, Carlos, "Beneficios y costes fiscales del colonialismo. Las remesas americanas a España, 1760-1814”, Revista de Historia Económica, XV/3 (Madrid, 1997): 475-505.

Marichal, Carlos, La bancarrota del Virreinato, México, Fondo de Cultura Económica, 1999.

Martínez Shaw, Carlos, El sistema comercial español del Pacífico (1765-1812), Madrid, Real Academia de la Historia, 2007.

Pagden, Anthony, "Identity Formation in Spanish America", N. Canny y A. Pagden (eds.), Colonial Identity in the Atlantic World, 1500-1800, Princeton, Princeton University Press, 1987: 51-93. 
Pagden, Anthony, Spanish Imperialism and the Political Imagination, New Haven y London, Yale University Press, 1990.

Pagden, Anthony, Lords of all the World. Ideologies of Empire in Spain, Britain and France c. 1500-c. 1800, New Haven, Yale University Press, 1995.

Paquette, Gabriel B., Enlightenment, Governance, and Reform in Spain and its Empire, 1759-1808, New York, Palgrave MacMillan, 2008.

Spengler, Joseph J., French Predecessors of Malthus, Durham, Duke University Press, 1942.

Stein, Stanley J. y Stein, Barbara J., Silver, Trade, and War, Baltimore y London, The Johns Hopkins University Press, 2000.

Stein, Stanley J. y Stein, Barbara J., El apogeo del imperio, Barcelona, Crítica, 2005.

Torres Sánchez, Rafael, "Campomanes y el comerciante y financiero Simón Aragorri”, M. D. Mateo (ed.), Campomanes, doscientos años después, Oviedo, Instituto Feijóo de Estudios del Siglo XVIII, 2006: 709-718.

Ulloa, Bernardo de, Restablecimiento de las fábricas y comercio español (1740), Madrid. IEF, 1992.

Usoz, Javier, "La nueva política ilustrada y la esfera pública: las introducciones a la Economía en el siglo XVIII español", Revista de Estudios Políticos, 153 (Madrid, 2011): 11-46.

Uztáriz, Jerónimo, Theórica y práctica de comercio y de marina (1724), Madrid, Imprenta de A. Sanz, 1742.

Vercruysse, Jeroom, “Journal de commerce (1759-1762)", J. Sgard (ed.), Dictionnaire des journaux 1600-1789, Paris, Universitas, 1991, nº 643.

Walker, Geoffrey J., Política española y comercio colonial, 1700-1789, Barcelona, Ariel, 1979.

Ward, Bernardo, Proyecto económico (1762), Madrid, Ibarra, 1779.

Wennerlind, Carl, "An Artificial Virtue and the Oil of Commerce: A Synthetic View of Hume's Theory of Money", C. Wennerlind y M. Schabas (eds.), David Hume's Political Economy, Londres, Routledge, 2008: 105-126.

Zahedieh, Nuala, "Economy", David Armitage y Michael J. Braddick (eds.), The British Atlantic World, 1500-1800, New York, Palgrave-MacMillan, 2002: 51-68.

Zylberberg, Michel, Une si douce domination, Paris, Ministère de Finances, 1993.

Fecha de recepción: 30 de noviembre de 2011.

Fecha de aceptación: 1 de junio de 2012. 


\section{Simón de Aragorri's Reflexiones (1761) and the reform of the Spanish Atlantic Commerce}

Reflexiones sobre el estado actual del comercio de España -Reflections about the Current State of the Commerce in Spain- is a hitherto unknown and vast economic and political treatise which was published in 1761 anonymously. His author was Simón de Aragorri. The serendipity of a print copy of the treatise let us assert that it aimed at having a bearing on the economic debate right after Carlos III's enthronement. This article analyzes the theoretical foundations and the reformists scheme put forward in the treatise relative to the overseas Spanish possessions.

KEY WORDS: political economy and its internacional circulation; atlantic history; spanish Enlightenment; economic reforms; Jacques Accarias de Serionne; David Hume. 